\title{
Effect of ethanol Adiantum capillus-veneris extract in experimental models of anxiety and depression
}

\author{
Zahra Rabiei $^{\oplus 1}$, Mahbubeh Setorki* \\ ${ }^{1}$ Medical Plants Research Center, Basic Health Sciences Institute, Shahrekord University of Medical Sciences, Shahrekord, \\ Iran, ${ }^{2}$ Department of Biology, Izeh Branch, Islamic Azad University, Izeh, Iran
}

\begin{abstract}
Depression is one of the most common psychiatric disorders with a prevalence of $15 \%-25 \%$. Monoamine aminotransferases, in particular, norepinephrine, serotonin, and dopamine, change in the brain of depressed people. Adiantum capillus-veneris is one of the species of the maidenhair fern genus that have traditionally been used to treat cough, cold symptoms, and local hair loss.In this experimental study, white male rats weighing 250-300 g were assigned to 5 groups of 10 each; group 1: Receiving normal saline; groups 2-4: Receiving A.capillus-veneris extract at 50, 100, and $200 \mathrm{mg} / \mathrm{kg}$, respectively; and group 5: Receiving fluoxetine at $10 \mathrm{mg} / \mathrm{kg}$. Chronic unpredictable stress (CUS) was induced by 3-week exposure to chronic stress. The forced swim test and plus maze were used to assess depression and anxiety, respectively. Malondialdehyde (MDA) levels and antioxidant capacity in the serum and brain were measured. Treatment with A.capillus-veneris extract at $200 \mathrm{mg} / \mathrm{kg}$ significantly reduced the duration of immobility. In the group given extract at $200 \mathrm{mg} / \mathrm{kg}$, a significant increase in the number of open arm entries was observed when compared to the control group. A.capillus-veneris extract at 50,100, and $200 \mathrm{mg} / \mathrm{kg}$ resulted in a significant increase in the time spent in the open arm. A.capillus-veneris extract reduced MDA levels and increased antioxidant levels of serum and brain in rat. A.capillus-veneris has significant antidepressant and anti-anxiety effects in rat, probably due to its antioxidant and anti-inflammatory activities.
\end{abstract}

Keywords: Adiantum capillus-veneris/extract/effects. Forced swim test.Anti-anxiety.

\section{INTRODUCTION}

Anxiety and depression are among the most common psychiatric diseases. More than $20 \%$ of adults suffer from these disorders during their lifespan. For years, anxiety and depression have been considered two different psychological conditions; benzodiazepines are used as selective drugs for acute anxiety and inhibitors of amine absorption and monoamine oxidase inhibitors are used to treat depression (Moraet al., 2005)

Depression is a multifactorial, chronic, and lifethreatening illness worldwide. Currently, $20 \%$ of the people across the globe are suffering from depression and is one of the leading 10 causes of mortality. According to the World Health Organization, depression is the second leading illness in developed countries in 2020 (Whyte, Mulsant, 2002). Besides that, forty million adults each year develop anxiety disorders who are also expected

*Correspondence: M. Setorki. Department of Biology, Izeh Branch, Islamic Azad University, Izeh, Iran. E-mail:doctor.setorgi@gmail.com to develop cardiovascular and psychiatric disorders (Weissman et al., 1990).

Nearly two-thirds of anxious and depressed people respond to current treatments, but recovery rate remains unsatisfactory. In addition, currently available drugs lead to various systemic side effects including development of dependence and tolerance in the long term (Goodman, 1996).

Oxidative stress is associated with central nervous system disorders, including neurodegenerative and neuropsychiatric disorders, such as schizophrenia and major depressive disorder. Recently, the role of oxidative stress in depression, anxiety disorders, and stress has been demonstrated. In 2005, Hovatta et al., found a close relationship between antioxidant defense mechanisms and anxiety-related phenotypes in mice. They found that in the brain, glutathione reductase- 1 and glyoxalase-1, which are the genes involved in antioxidant metabolism, were significantly correlated with anxiety-related phenotypes (Hovatta et al., 2005).

Desrumaux et al. (2005) showed that vitamin E 
deficiency in the mouse brain significantly increased the levels of central oxidative stress markers and thus induced anxiety behaviors without disrupting the motor activity of the animal (Desrumaux et al.,2005).

Antidepressant drugs are widely used to treat stress and stress-related depression and anxiety.Fluoxetine, a non-tricyclic antidepressant drug, effectively treats a wide range of mood disorders and prevents the adverse effects of different types of stressors.In addition, it attenuates some effects of stress on the immune system and prevents oxidative damage (Zafir, Banu 2007).

Fluoxetine acts by inhibiting 5-hydroxytraptamine (5-HT) reuptake in the central nervous system. Chronic treatment with fluoxetine may lead to changes in the properties of pre- and postsynaptic $5-\mathrm{HT}_{1 \mathrm{~A}}$ receptors due to modifications in the receptor-G protein coupling process (Castro et al., 2003).

The use of medicinal plants for the treatment of diseases dates back to many centuries ago. Today, although most of the used drugs are chemical, it is estimated that at least one third of all medicinal products are plant-based or are altered after isolation from the plant (Eisenberg et al., 1998).

Adiantum capillus-veneris is a woody plant with a $35 \mathrm{~cm}$ height, which has a rhizome. Its dried root is used as drug. The bases of its leaves are covered by wool. This plant occurs in southern Europe, the Alps, and Atlantic Coast as well as in Iran. This plant is, in fact, a type of perennial species of the maidenhair fern genus that grows in humid and organic material-rich environments as well as near the streams and rivers, such as wet walls. The plant resembles green cilantro (Shiraziet al., 2010).

The compounds of A.capillus-veneris include flavonoids, proanthocyanidins, hydroxycinnamic acid esters, bitter substance, gallic acid, tannins, hydrocarbons, and esters. This plant has expectorant properties and is used as a diuretic, tonic, and refrigerant agent as well as for liver and spleen diseases. In traditional medicine, it is used, as tea, to treat respiratory diseases, and as syrup, to treat severe coughs. It was also used to enhance the hair's black color and hair growth due to its similarity to head hair. No side effects due to the use of this plant have been reported, but it has contraindication during pregnancy. All parts of the plant are usable (Shirazi et al., 2010). In women and female mice, this plant has been found to reduce follicle-stimulating hormone levels and increase sex hormone-binding globulin levels. The oral use of $A$. capillus-veneris has been observed to exert hypoglycemic effects in male mice and to stimulate the heart in rabbits. In vitro, this plant has been found to exert an inhibitory effect on Streptococcus pyogenus, Corynebacterium ovis, Bacillus spp, and Aspergillus flavus. A. capillus-veneris extract has significant effects on patients with asthma as well (Shirazi et al., 2010).

Because the antidepressant and anti-anxiety effects of the unprocessed A. capillus-veneris have not yet been investigated, we investigated these effects in vivo.

\section{MATERIAL AND METHODS}

\section{Preparation of extract}

A. capillus-veneris was purchased from a reliable grocery and then, $1000 \mathrm{~g}$ of the dried plant was dissolved in $2000 \mathrm{~mL}$ of $70 \%$ ethanol. After the solution was left at room temperature for 48 hours, it was filtered and its solvent was removed using rotary evaporator. Then, the resulting extract was thoroughly dried under $40^{\circ} \mathrm{C}$ and the extract at required concentrations was prepared (Ahmed et al., 2013).

\section{Determination of radical scavenging activityof A. capillus-veneris extract}

A. capillus-veneris extract $(10,20,30,40,50,70$, $80 \mu \mathrm{g} / \mathrm{mL}$ ) was first prepared and equal amount of the DPPH solution $(1 \mathrm{mg} / \mathrm{mL})$ was added to $A$. capillus-veneris extract at all concentrations. The resulting solution was kept in the dark at room temperature for 15 minutes, the optical absorbance was measured at $517 \mathrm{~nm}$ using a spectrophotometer and then the activity of the DPPH radical inhibition was calculated.

$$
\operatorname{IC50}(\%)=\left(\mathrm{A}_{\text {control }}-\mathrm{A}_{\text {sample }}\right) / \text { Acontrol } \times 100
$$

where: IC50 is the concentration of the solution in which $50 \%$ of the DPPH radical is scavenged (Mokhtari et al., 2017).

\section{ANIMALS}

In this study, male rats weighing $250 \pm 300 \mathrm{~g}$ were used. The rats were maintained in the Animal House of the Azad University of Izeh under $24^{\circ} \mathrm{C}$ temperature and 12-h dark/12-h light cycle with free access to water and food. In addition, each rat was tested only once.

\section{Induction of depression}

In this study, depression was induced by exposure to chronic stress. Conventionally, rats were exposed to one of the stressful factors below daily for 3 weeks. 
Effect of ethanol Adiantum capillus-veneris extract in experimental models of anxiety and depression

TABLE I -Weekly program for stress induction in experimental groups

\begin{tabular}{lccccccc}
\hline week & Saturday & Sunday & Monday & Tuesday & Wednesday & Thursday & Friday \\
\hline 1 & $\mathrm{~A}_{2}$ & $\mathrm{~B}_{2}$ & $\mathrm{~A}$ & $\mathrm{~B}$ & $\mathrm{C}$ & $\mathrm{D}$ & $\mathrm{E}$ \\
2 & $\mathrm{~A}$ & $\mathrm{C}$ & $\mathrm{A}$ & $\mathrm{D}$ & $\mathrm{B}_{3}$ & $\mathrm{~A}_{1}$ & $\mathrm{E}$ \\
3 & $\mathrm{D}$ & $\mathrm{C}$ & $\mathrm{D}$ & $\mathrm{A}$ & $\mathrm{B}_{2}$ & $\mathrm{~A}_{2}$ & $\mathrm{E}$ \\
\hline
\end{tabular}

A: Swimming in cold water $\left(12^{\circ} \mathrm{C}\right)$ for $5 \mathrm{~min}$; A1: Swimming in water with room temperature $\left(23 \pm 2^{\circ} \mathrm{C}\right)$ for $10 \mathrm{~min}$; A2: Swimming in water with room temperature $\left(23 \pm 2{ }^{\circ} \mathrm{C}\right)$ for $15 \mathrm{~min}$; B: Tail pinch $(30 \mathrm{~seconds})$; B2: Tail pinch $(60$ seconds); B3: Tail pinch (90 seconds); C: Water and food deprivation (24 h); D: Overnight awakening; E: No stress (Rabiei, Naderi, Rafieian-Kopaei, 2017).

The rats weighing $250 \pm 300 \mathrm{~g}$ were divided to five groups of 10 each: Group 1 (control): Intraperitoneally receiving normal saline; groups 2-4 (AC50, AC100, AC200): Intraperitoneally injected with different (respectively, 50, 100, and $200 \mathrm{mg} / \mathrm{kg}$ ) doses of $A$. capillus-veneris(AC); and group 5 (fluoxetine): Receiving fluoxetine $(10 \mathrm{mg} / \mathrm{kg})$.

\section{Forced swim test (FST)}

This animal test is one of the most reliable and common tests for evaluation of depression. Based on learned helplessness theory of Martin Seligman, if animal is exposed to chronic stress and fails to escape, it will gradually loses its hope to escape, stops its activity and mobility, and becomes frustrated and immobile. To measure immobility time, all time intervals when rat is immobile are recorded within a specified duration. Extended immobility time represents depression and its decrease represents the efficacy of treatment with antidepressant. In this test, a glass container with a length of $25 \mathrm{~cm}$, a width of $12 \mathrm{~cm}$, and a height of $15 \mathrm{~cm}$ is filled with $25{ }^{\circ} \mathrm{C}$ water and the rat is slowly placed in the water from a $20-\mathrm{cm}$ distance to the water surface. Conventionally, lack of paddling is considered immobility. All chronological measurements were conducted by one person. Total FST lasts seven minutes and the first two minutes are specified for adaptation to the test conditions and therefore immobility time during this period is not recorded. The data on all variables were recorded by one person (Rabiei, Gholami, Rafieian-Kopaei, 2016).

\section{Plus maze test}

In order to assess the level of anxiety, a device called the plus maze, which is a standard model to assess the level of anxiety in rodents, was used. This device consists of two open arms $(5 \times 50 \mathrm{~cm})$, two closed arms $(50 \times 5 \times 40 \mathrm{~cm})$, and a central platform $(5 \times 5 \mathrm{~cm})$. The open arms and the closed arms are facing up to $50 \mathrm{~cm}$ above the floor. This model is an unconditional measure of anxiety that requires no animal training or learning. After administering the drugs to the rat on the day of the test, the rats were transferred to the behavior room separately 5 minutes before the test and placed in a Plexiglas black box $(40 \times 40 \times 30 \mathrm{~cm})$ to enhance its exploring activity. Then, in order to measure the level of anxiety, the rat was placed in the elevated plus maze (in the platform facing the open arm) and the time spent exploring, the number of open arm entries, and the time spent in the open arm were recorded. An increase in the entry into the open arm and the time spent in this arm was considered to indicate anxiety reduction in the rat (Taïwe et al., 2010).

\section{Motor coordination test by the rotarod apparatus}

The power of the rats to maintain balance and motor resistance was also studied. Rotarod is a device that measures the motor resistance and balance maintenance of animals. This device has a carrousel with a rotation speed of $0-40 \mathrm{r} / \mathrm{min}$. This device has a belt and the rotation speed can be regulated by changing its place. To make the animal familiar with the device, they were placed on the trundling shaft and trained to move on it. The rotation speed was considered to be $10 \mathrm{r} / \mathrm{min}$ with the $7 \mathrm{r} / \mathrm{min}^{2}$ acceleration, which is almost 10-11 revolutions $/ \mathrm{min}$. In each of the experimental groups, the rats were placed on carrousel of the rotarod device $1 \mathrm{~h}$ after injection of the extract. The carrousel turned for $300 \mathrm{~s}$ and the duration that animal could maintain his balance and resist against the movement of carrousel was considered the rat's resistance time. The maximum time considered for each animal in this test was $300 \mathrm{~s}$ (Rabiei, Rafieian, 2014).

\section{Measuring the antioxidant capacity of the serum and the brain}

Three solutions were used to measure serum antioxidant capacity consisting of: 1 . Buffer $(1.55 \mathrm{~mL}$ of sodium acetate and $8 \mathrm{~mL}$ of concentrated acetic acid reaching $500 \mathrm{~mL}$ volume using distilled water; 2. Iron chloride solution [270 $\mathrm{mg}$ of iron (III) chloride reaching $50 \mathrm{~mL}$ volume by addition of distilled water]; and 3.Triazine ( $47 \mathrm{mg}$ of triazine dissolved in $40 \mathrm{~mL}$ of 
$40 \mathrm{mM}$ hydrochloric acid). Stock solution was prepared by adding $10 \mathrm{~mL}$ of solution $1,1 \mathrm{~mL}$ of solution 2, and $1 \mathrm{~mL}$ of solution $3.25 \mu \mathrm{L}$ of serum sample or brain homogenate was added to $1.5 \mathrm{~mL}$ of the stock solution and the optical absorbance was read at $593 \mathrm{~nm}$ after the stock solution was left at $37^{\circ} \mathrm{C}$ for 10 minutes (Mokhtariet al., 2017).

\section{Measuring serum malondialdehyde (MDA) level}

Briefly, $0.5 \mathrm{~g}$ of thiobarbituric acid (TBA) was dissolved in $80 \mathrm{~mL}$ of acetic acid $20 \%$, its $\mathrm{pH}$ was set at 5.3 by using sodium hydroxide, and its volume reached $100 \mathrm{~mL}$ by addition of acetic acid $20 \% .100 \mu \mathrm{L}$ of the serum sample was mixed with $100 \mu \mathrm{L}$ of $1.8 \%$ SDS solution and $2.5 \mathrm{~mL}$ of the stock solution. The samples were placed in water bath for 1 hour and then cooled and centrifuged at $4000 \mathrm{rpm}$. The optical absorbance of the supernatant was read at $523 \mathrm{~nm}$ (Mokhtari et al., 2017).

\section{Measuring brain MDA level}

To measure brain MDA level, $1 \mathrm{~g}$ of the brain tissue was homogenized in cooled $2.5 \% \mathrm{KCl}(10 \% \mathrm{w} / \mathrm{v})$ and incubated in a metabolic shaker at $(37 \pm 1)^{\circ} \mathrm{C}$ for $60 \mathrm{~min}$. Then, $1 \mathrm{~mL}$ of $5 \%$ trichloroacetic acid and $1 \mathrm{~mL}$ of $67 \%$ TBA were added into the metabolic shaker and after each addition, the solution was mixed well. The mixture of each vial was transferred to a tube and centrifuged at 2,000 rpm for $15 \mathrm{~min}$; finally, the supernatant was transferred to another tube and placed in a boiling water bath. Ten minutes later, the tubes were cooled down and their absorbance was read at $535 \mathrm{~nm}$ (Mokhtari et al., 2017).

\section{Data analysis}

Data analysis was performed using the SPSS version 16. First, distribution normality of the data was tested by using Kolmogorov-Smirnov test and then homogeneity of variances was investigated by using Levene's test. Then, one-way ANOVA was used to determine the significant difference between treatments and Tukey's test was used to compare the mean values. Data were expressed as mean ( \pm standard error) and $P<0.05$ was considered significance level.

\section{RESULTS}

\section{DPPH radical scavenging activities for various concentrationsof A. capillus-veneris extract}

The results demonstrated that the anti-radical activity of $A$. capillus-veneris extract increased with increasing its concentration. In addition, the EC50 of
A. capillus-veneris extract was derived $54.61 \mathrm{ug} / \mathrm{mL}$. IC50 was directly correlated with A. capillus-veneris extract antioxidant activity.

The results of the effect of $A$. capillus-veneris extract on the duration of immobility in the FST are shown in Figure 1. The results showed that fluoxetine decreased the immobility duration significantly when compared to the control group. A. capillusveneris extract at $200 \mathrm{mg} / \mathrm{kg}$ significantly reduced the duration of immobility when compared to the control group. The extract at 50 and $100 \mathrm{mg} / \mathrm{kg}$ had no significant effect on immobility duration.

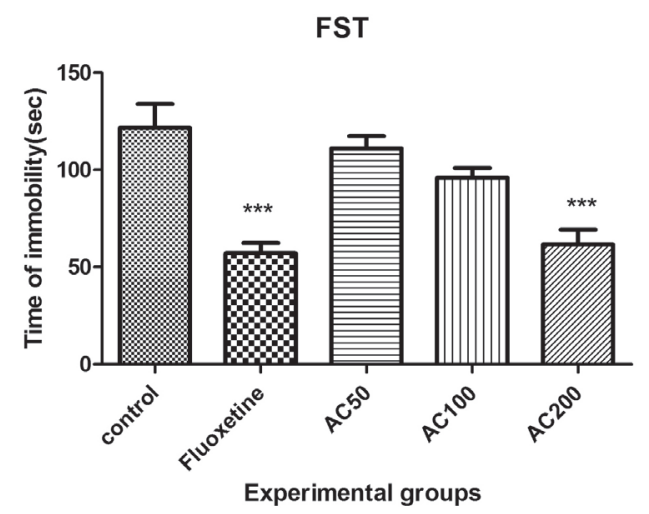

FIGURE 1 - Effect of Adiantum capillus-veneris extract on Immobility Duration in the Forced Swim Test. ${ }^{* * *}=(P<0.001)$; AC: Adiantum capillus-veneris.

The results from the effect of A. capillus-veneris extract on the number of open arm entries and the time spent in the open and closed arms of the plus maze are shown in Figure 2 (A-D). The results showed that in the fluoxetine receiving mice, the number of open arm entries and the time spent in the open arm increased significantly when compared to the control group. In the group given the extract at $200 \mathrm{mg} / \mathrm{kg}$, a significant increase in the number of open arm entries was observed when compared to the control group. A. capillus-veneris extract at 50, 100, and $200 \mathrm{mg} / \mathrm{kg}$ resulted in a significant increase in the time spent in the open arm of the plus maze when compared to the control group. Fluoxetine significantly reduced the time spent in the closed arm and the number of closed arm entries when compared to the control group. A. capillusveneris extract at 100 and $200 \mathrm{mg} / \mathrm{kg}$ caused a significant decrease in the number of closed arm entries. This extract at 50,100 , and $200 \mathrm{mg} / \mathrm{kg}$ significantly reduced the time spent in the closed arm.

The results of the effect of $A$. capillus-veneris extract on the motor activity in the rotarod test are shown in Figure 3. The results showed that fluoxetine caused a significant increase in motor activity when compared 

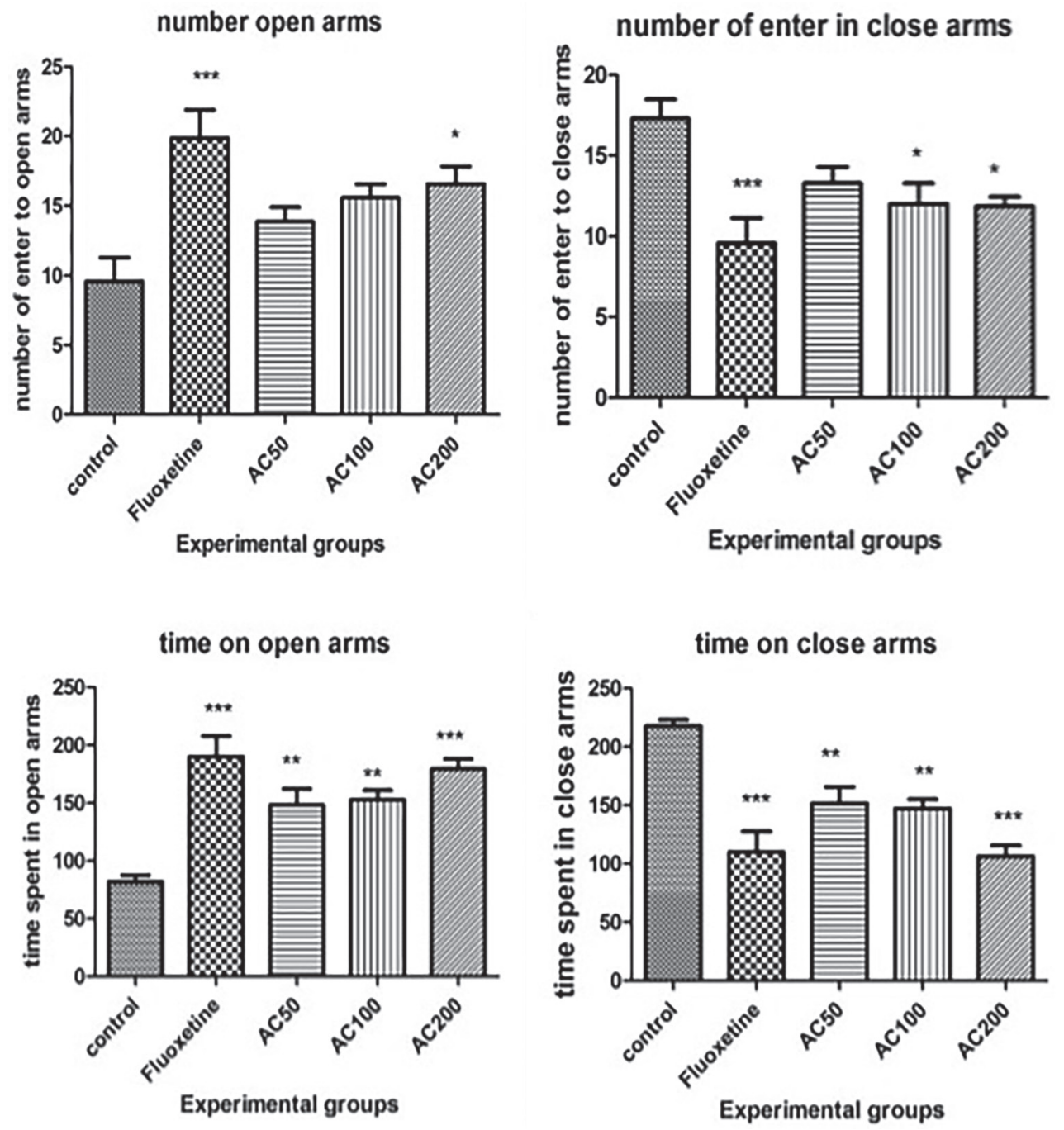

FIGURE 2 - Effect of Adiantum capillus-veneris extract on the Amount of Time Spent in the Open Arm and the Number of Open Arm Entries in Plus Maze. ${ }^{* * *}=(P<0.001) ;{ }^{* *}=(P<0.01) ;{ }^{*}=(P<0.05), \mathrm{AC}$ : Adiantum capillus-veneris.



FIGURE 3 - Effect of Adiantum capillus-veneris extract on motor activity in Plus Maze. ${ }^{* * *}=(P<0.001) ;{ }^{*}=(P<0.05)$; AC: Adiantum capillus-veneris.

to the control group. The extract at $200 \mathrm{mg} / \mathrm{kg}$ caused a significant increase in motor activity when compared to the control group. The extract at 100 and $50 \mathrm{mg} / \mathrm{kg}$ had no significant effect on motor activity.

The results regarding the effect of $A$. capillus-veneris extract on the antioxidant capacity in serum and brain are shown in Figure 4 (A, B). The results of this study showed that fluoxetine significantly increased the antioxidant capacity of the serum and brain tissue when compared to the control group. The extract at $200 \mathrm{mg} / \mathrm{kg}$ resulted in a significant increase in the antioxidant capacity of the brain tissue. In the groups given the extract at 100 and $200 \mathrm{mg} /$ $\mathrm{kg}$, a significantly higher antioxidant level was observed when compared to the control group.

The results on the effect of $A$. capillus-veneris extract on the brain and serum levels of MDA in mice are shown in Figure 5 (A, B). The results of this study showed that fluoxetine caused a significant decrease in the levels of MDA in brain and serum when compared to the control group. A. capillus-veneris extract at 100 and $200 \mathrm{mg} / \mathrm{kg}$ 



FIGURE 4 (A, B) - Effect of Adiantumcapillus-venerisextract on serum and brain antioxidant levels; ${ }^{* * *}=(P<0.001){ }^{* *}=(P<0.01)$; AC: Adiantumcapillus-veneris.


FIGURE 5 (A, B) - 5- The effect of Adiantum capillus-veneris extract on serum and brain malondialdehyde levels; ${ }^{* * *}=(P<0.001)$; ${ }^{* *}=(P<0.01){ }^{*}=(P<0.05) ;$ AC: Adiantum capillus-veneris.

significantly reduced the levels of MDA in brain and serum when compared to the control group. The extract at $50 \mathrm{mg} /$ $\mathrm{kg}$ did not have any significant effect on the serum and brain MDA levels.

\section{DISCUSSION}

The aim of this study was to investigate the effect of A.capillus-veneris extract on depression and anxiety in rat. Stress induction in rats caused a significant increase in the duration of immobility in the FST.

Stress induction also caused a significant increase in the number of closed arm entries and the time spent in this arm in the plus maze. A.capillus-veneris extract treatment significantly increased the time spent in the open arm and the number of entries into this arm. Stress induction also significantly increased serum and brain MDA levels, and reduced the antioxidant capacity of the serum and brain. A.capillus-veneris extract treatment reduced MDA levels and increased antioxidant capacity in serum and brain.

Many of the drugs currently used to treat depression lead to certain side effects that cause many patients not to accept pharmacotherapy. But complementary therapies are widely used and are effective to treat mental disorders, anxiety, and insomnia, with fewer side effects than routine drugs (Rabiei, Rabiei 2017). In similar studies, FST has been used as one of the most popular tests of depression in rodents. Rodents, when forced to swim in a cylinder where they are not able to escape from, are immobilized after a period of intense activity, which reflects hopeless behaviors. Antidepressants increase the rates of mobility and escaping in these animals. Decreased immobility duration is a reliable predictor to evaluate antidepressants (Moinuddin, Devi, Khajuria, 2012).

In the present study, treatment of rat with fluoxetine $(20 \mathrm{mg} / \mathrm{kg})$-induced stress prior to behavioral tests significantly reduced the duration of immobility in the FST. Fluoxetine also significantly reduced the number of 
closed arm entries and the amount of time spent in this arm in the plus maze. Fluoxetine decreased MDA levels and increased the antioxidant capacity in brain and serum significantly.

Oxidative stress is an effective factor on the development of various diseases in the central nervous system and can accelerate the aging process and behaviors associated with depression and anxiety. Oxidative stress occurs when the production of oxidative reactive substances exceeds the antioxidant defense capacity to suppress the toxins. During oxidative stress, the production of free radicals exceeds the body's antioxidant system capacity, such as vitamins $\mathrm{C}$ and $\mathrm{E}$, and glutathione (Pandya, Howell, Pillai, 2013). The reactive oxygen species and reactive nitrogen species cause oxidation of proteins and membrane lipids, DNA damage, and even cell apoptosis. MDA is a small but stable product of lipid peroxidation that is produced by degradation of the unstable peroxides of unsaturated fatty acids. Excessive lipid peroxidation in nerve cells can lead to cell death. In order to fight free radicals and reactive oxygen species, antioxidant defense mechanisms neutralize or minimize the adverse effects of these invasive agents. Superoxide dismutase, glutathione peroxidase, and catalase are some of the constituents of this defense system. Certain antioxidants are also supplied by various foods (de Graaf et al., 2002).

Oxidative stress has been reported to occur in over 100 diseases, including cancer, neurodegenerative diseases, many psychological problems, and autoimmune diseases. It is noteworthy that in people with anxiety and depression, various degrees of oxidative damage and a decrease in the level of antioxidant enzymes have been observed (Bouayed, Rammal, Soulimani, 2009).

In the present study, the extract of A.capillus-veneris produced favorable antidepressant and anti-anxiety effects in the FST and plus maze, which was associated by a decrease in the brain and serum MDA levels and an increase in their antioxidant capacity. The antioxidant effects of A.capillus-veneris have also been shown in a number of previous studies (Khodaie, Esnaashari, Moghaddam, 2015).

The antioxidant capacity of A.capillus-veneris leaf extract in vitro was investigated on $\mathrm{H} 2 \mathrm{O} 2$-induced oxidative complications in peripheral blood lymphocytes. Pre-treatment with leaf extract of this plant inhibited lipid peroxidation and increased the activity of antioxidant enzymes and glutathione content significantly (Lin, Ding, 2008).

The ethanol extract of A.capillus-veneris exhibits high antioxidant activity compared to ascorbic acid, with an IC50 of approximately $0.3868 \mathrm{mg} / \mathrm{g}$ in the DPPH assay and $0.695 \mathrm{mg} / \mathrm{g}$ in the ABTS assay. Antioxidant activity of A.capillus-veneris can be due to polyphenols and flavonoids. Flavonoids have antioxidant, antiinflammatory, and cell protective properties (Ibraheim, Ahmed, Gouda, 2011).

A.capillus-veneris leaves contain various flavonoids such as rutin, quercetin, quercetin-3-O-glucoside, cactorium, isocrathin, NicoFlavourin, naringin, astragalin, popninin, procyanidin, prodelphinidin, and kaempferol3-sulfate (Al-Snafi, 2015). In previous studies, the antidepressant effects of these flavonoids, including rutin, quercetin, and naringin (Machado et al., 2008; Aggarwal, Gaur, Kumar, 2010; Bhutada et al., 2010), have been confirmed.

Immune system impairment is one of the most important problems that cause depression. Studies have shown that depression, on the one hand, suppresses the appropriate response to infectious agents, by inducing responses to type $2 \mathrm{~T}$ helper cells (responses involved in allergies and certain antibody-dependent autoimmunities), and, on the other hand, causes chronic and malignant inflammation by the immune system in a way that inflammation itself leads to exacerbation of depression (Liu et al., 2015).

Chronic inflammation is one of the physical problems caused by depression. On the other hand, researchers argue that chronic inflammation can be one of the causes of depression (Rizzo et al., 2012). Studies have shown that several molecules are involved in inflammation in patients with depression, the most important of which are inflammatory cytokines (Liu et al., 2015).

In the study of Liu et al. (2015), the injection of cytokines IL-6, IL-1 $\beta$, and TNF- $\alpha$ and lipopolysaccharide induced depression and anxiety-related behaviors in mice (Liu et al., 2015). In patients with depression, high levels of IL-6, IL-1 $\beta$, and TNF- $\alpha$ have also been observed.

In a study by Arora et al. (2011), reserpineinduced depression significantly increased the levels of inflammatory factors such as IL-6, TNF- $\alpha$, and IL- $1 \beta$ in mice (Arora et al., 2011).

Antidepressant drugs, such as fluoxetine and paroxetine, have also been reported to reduce levels of inflammatory cytokines in the brain and serum of mice with depression (Hwang et al., 2008)

In the study of Haider et al. (2013) ethanol A.capillusveneris extract was observed to exert strong antiinflammatory effects, in comparison with indomethacin, in the mouse model of carrageenan-induced paw edema (Haider et al., 2013). 


\section{CONCLUSION}

It can be argued that the A. capillus-veneris extract reduces the symptoms of depression and anxiety by decreasing the oxidative stress markers in rats under stress, so that treatment with fluoxetine and A. capillus-veneris reduces the oxidative damage caused by stress, which is an important mechanism with respect to pharmaceutical and protective effects of fluoxetine and A. capillus-veneris extract in treating disorders due to stress.

\section{REFERENCES}

Aggarwal A, Gaur V, Kumar A. Nitric oxide mechanism in the protective effect of naringin against post-stroke depression (PSD) in mice. Life Sci. 2010;86(25):928-35.

Ahmed A, Wadud A, Jahan N, Bilal A, Hajera S. Efficacy of Adiantumcapillusveneris Linn in chemically induced urolithiasis in rats. J Ethnopharmacol. 2013;146(1):411-6.

Al-Snafi AE. The chemical constituents and pharmacological effects of Adiantumcapillus-veneris-A review. Asian J Pharm Clin Res. 2015;5(2):106-11.

Arora V, Kuhad A, Tiwari V, Chopra K. Curcumin ameliorates reserpine-induced pain-depression dyad: Behavioural, biochemical, neurochemical and molecular evidences. Psychoneuroendocrinology. 2011;36(10):1570-81.

Bhutada P, Mundhada Y, Bansod K, Ubgade A, Quazi M, Umathe $\mathrm{S}$, et al. Reversal by quercetin of corticotrophin releasing factor induced anxiety-and depression-like effect in mice. Prog NeuropsychopharmacolBiol Psychiatry. 2010;34(6):955-60.

Bouayed J, Rammal H, Soulimani R. Oxidative stress and anxiety: relationship and cellular pathways. Oxid Med Cell Longev. 2009;2(2):63-7.

Castro ME, Diaz A, delOlmo E, Pazos A. Chronic fluoxetine induces opposite changes in $\mathrm{G}$ protein coupling at pre and postsynaptic 5-HT1A receptors in rat brain. Neuropharmacology. 2003;44(1):93-101.

deGraaf R, Bijl RV, SmitF, Vollebergh WA, Spijker J. Risk factors for 12-month comorbidity of mood, anxiety, and substance use disorders: findings from the Netherlands Mental Health Survey and Incidence Study. Am J Psychiatry. 2002;159(4):620-9.
Desrumaux C, Risold P-Y, Schroeder H, Deckert V, Masson D, Athias A, et al. Phospholipid transfer protein (PLTP) deficiency reduces brain vitamin $\mathrm{E}$ content and increases anxiety in mice. FASEB J. 2005;19(2):296-7.

Eisenberg DM, Davis RB, Ettner SL, Appel S, Wilkey S, Van Rompay M, et al. Trends in alternative medicine use in the United States, 1990-1997: results of a follow-up national survey. Jama. 1998;280(18):1569-75.

Goodman LS. Goodman and Gilman's the pharmacological basis of therapeutics: New York: McGraw-Hill; 1996.

Haider S, Kharbanda C, Alam MS, Hamid H, Ali M, Alam M, et al. Anti-inflammatory and anti-nociceptive activities of two new triterpenoids from Adiantumcapillus-veneris Linn. Nat Prod Res. 2013;27(24):2304-10.

Hovatta I, Tennant RS, Helton R, Marr RA, Singer O, Redwine $\mathrm{JM}$, et al. Glyoxalase 1 and glutathione reductase 1 regulate anxiety in mice. Nature. 2005;438(7068):662-6.

Hwang J, Zheng LT, Ock J, Lee MG, Kim S-H, Lee H-W, et al. Inhibition of glial inflammatory activation and neurotoxicity by tricyclic antidepressants. Neuropharmacology. 2008;55(5):82634.

Ibraheim ZZ, Ahmed AS, Gouda YG. Phytochemical and biological studies of Adiantumcapillus-veneris L. Saudi Pharm J. 2011;19(2):65-74.

Khodaie L, Esnaashari S, Moghaddam SB. Essential oil of arial parts of adiantumcapillus-veneris: chemicalcomposition and antioxidant activity. Jundishapur J Nat Pharm Prod. 2015;10(4):e21968.

Lin Y, Ding L. Extraction and determination on clearance rate of hydroxyl radicals of flavonoid from Adiantamcapillus-veneris. Food Mach. 2008;24:63-66.

Liu B, Xu C, Wu X, Liu F, Du Y, Sun J, et al. Icariin exerts an antidepressant effect in an unpredictable chronic mild stress model of depression in rats and isassociated with the regulation of hippocampal neuroinflammation. Neuroscience. 2015;294:193-205.

Machado DG, Bettio LE, Cunha MP, Santos AR, Pizzolatti MG, Brighente IM, et al. Antidepressant-like effect of rutin isolated from the ethanolic extract from Schinusmolle L. in mice: evidence for the involvement of the serotonergic and noradrenergic systems. Eur J Pharmacol. 2008;587(1):163-8. 
Moinuddin G, Devi K, Khajuria DK. Evaluation of the antidepressant activity of Myristicafragrans (Nutmeg) in male rats. Avicenna J Phytomed. 2012;2(2):72.

Mokhtari S, Rabiei Z, Shahrani M, Rafieian-Kopaei M. The ameliorating effect of beta vulgaris extract on memory and learning impairment induced by lesions of the nucleus basalis of meynert in rat. Int J ClinDiag Res. 2017;11(11).

Mora S, Díaz-Véliz G, Millán R, Lungenstrass H, Quirós S, Coto-Morales T, et al. Anxiolytic and antidepressant-like effects of the hydroalcoholic extract from Aloysiapolystachya in rats. Pharmacol Biochem Behav. 2005;82(2):373-8.

Pandya CD, Howell KR, Pillai A. Antioxidants as potential therapeutics for neuropsychiatric disorders. Prog Neuropsycho pharmacol Biol Psychiatry. 2013;46:214-23.

Rabiei Z, Gholami M, Rafieian-Kopaei M. Antidepressant effects of Menthapulegium in mice.Bangladesh J Pharmacol. 2016;11(3)711-15.

Rabiei Z, Naderi S, Rafieian-Kopaei M. Study of antidepressant effects of grape seed oil in male mice using tail suspension and forced swim tests. Bangladesh J Pharmacol. 2017;12(4):397402.

Rabiei Z, Rabiei S. A review on antidepressant effect of medicinal plants. Bangladesh J Pharmacol. 2017;12(1):1-11.

Rabiei Z, Rafieian M. Effects of Zizyphusjujuba extract on motor coordination impairment induced by bilateral electric lesions of the nucleus basalis of meynert in rat. Physiol Pharmacol. 2014;17(4):469-77.
Rizzo SS, Neal S, Hughes Z, Beyna M, Rosenzweig-Lipson S, Moss S, et al. Evidence for sustained elevation of IL-6 in the CNS as a key contributor of depressive-like phenotypes.Transl Psychiatry. 2012;2(12):e199.

Shirazi MH, Amin Gh, AkhondyLavasani B, Eshraghi Seyed S. Study of the inhibitory effect of Adiantum capillus-veneris extract on gram-positive and gram negative bacteria.Med Plan J. 2010;4(40):124-132.

Taïwe G, Bum E, Dimo T, Talla E, Weiss N, Dawe A, et al. Antidepressant, myorelaxant and anti-anxiety-like effects of Nauclealatifolia smith (Rubiaceae) roots extract in murine models. Int J Pharmacol. 2010;6(4):364-71.

Weissman MM, Markowitz JS, Ouellette R, Greenwald S, Kahn JP. Panic disorder and cardiovascular/cerebrovascular problems: results from a community survey. Am J Psychiatry. 1990;147(11):1504.

Whyte EM, Mulsant BH. Post stroke depression: epidemiology, pathophysiology, and biological treatment. Biol Psychiatry. 2002;52(3):253-64.

Zafir A, Banu N. Antioxidant potential of fluoxetine in comparison to Curcuma longa in restraint-stressed rats. Eur J Pharmacol. 2007;572(1):23-31.

Received for publication on $16^{\text {th }}$ February 2018 Accepted for publication on $19^{\text {th }}$ April 2018 